\title{
Timing the initiation of renal replacement therapy for acute kidney injury in Canadian intensive care units: a multicentre observational study
}

\section{Quand commence le traitement de l'insuffisance rénale en cas de lésion rénale aiguë dans les unités de soins intensifs au Canada? Une étude observationnelle multicentrique}

\author{
Edward Clark, MD • Ron Wald, MD • Adeera Levin, MD • Josée Bouchard, MD • \\ Neill K. J. Adhikari, MD • Michelle Hladunewich, MD • Robert M. A. Richardson, MD • \\ Matthew T. James, MD • Michael W. Walsh, MD • Andrew A. House, MD • \\ Louise Moist, MD • Daniel E. Stollery, MD • Karen E. A. Burns, MD • \\ Jan O. Friedrich, MD • James Barton, MD • Jean-Philippe Lafrance, MD • \\ Neesh Pannu, MD • Sean M. Bagshaw, MD • For the Canadian Acute Kidney Injury (CANAKI) Investigators
}

Received: 22 March 2012/ Accepted: 20 June 2012/Published online: 30 June 2012

(c) Canadian Anesthesiologists' Society 2012

\begin{abstract}
Purpose The optimal timing for starting renal replacement therapy (RRT) in patients with acute kidney injury (AKI) is unknown. Defining current practice is necessary to design interventional trials. We describe the current
\end{abstract}

Electronic supplementary material The online version of this article (doi:10.1007/s12630-012-9750-4) contains supplementary material, which is available to authorized users.

The Canadian Acute Kidney Injury (CANAKI) Investigators include (alphabetically): Sean M. Bagshaw (University of Alberta Hospital, Edmonton), Jim Barton (St. Paul's Hospital, Saskatoon), Edward Clark (University of Ottawa, Ottawa), Andrew A. House (London Health Sciences Centre, London), Matthew T. James (University of Calgary, Calgary), Adeera Levin (St. Paul's Hospital, Vancouver), Louise Moist (London Health Sciences Centre, London), Neesh Pannu (University of Alberta Hospital, Edmonton), Daniel Stollery (Grey Nuns Community Hospital), Michael W. Walsh (McMaster University, Hamilton), Ron Wald (St. Michael's Hospital, Toronto).

Author contributions Edward Clark contributed to acquisition, analysis, and interpretation of data; drafting the article; and final approval of the version to be published. Ron Wald, Adeera Levin, Josée Bouchard, Neill Adhikari, Michelle Hladunewich, Robert M.A. Richardson, Matthew T. James, Michael W. Walsh, Andrew A. House, Louise Moist, Daniel E. Stollery, Karen E.A. Burns, Jan O. Friedrich, James Barton, Jean-Philippe Lafrance, and Neesh Pannu contributed to acquisition of data; revising the article critically for important intellectual content; and final approval of the version to be published. Sean M. Bagshaw contributed to the conception and design of the study, acquisition, analysis, and interpretation of data; revising the article critically for important intellectual content; and final approval of the version to be published.
Canadian practice regarding the timing of RRT initiation for $A K I$.

Methods An observational study of patients undergoing RRT for AKI was undertaken at 11 intensive care units (ICUs) across Canada. Data were captured on

\section{E. Clark, MD}

Kidney Research Centre, Ottawa Hospital Research Institute, University of Ottawa, Ottawa, ON, Canada

\section{R. Wald, MD - K. E. A. Burns, MD - J. O. Friedrich, MD} University of Toronto and the Keenan Research Centre in the Li Ka Shing Knowledge Institute, St. Michael's Hospital, Toronto, ON, Canada

A. Levin, MD

St. Paul's Hospital, Vancouver, BC, Canada

J. Bouchard, MD

Hôpital du Sacré-Coeur, Université de Montréal,

Montreal, QC, Canada

N. K. J. Adhikari, MD

Department of Critical Care Medicine, Sunnybrook Health

Sciences Centre, University of Toronto, Toronto, ON, Canada

M. Hladunewich, MD

Division of Nephrology, Sunnybrook Health Sciences Centre, University of Toronto, Toronto, ON, Canada

R. M. A. Richardson, MD

Toronto General Hospital, University of Toronto,

Toronto, ON, Canada 
demographics, clinical and laboratory findings, indications for RRT, and timing of RRT initiation.

Results Among 119 consecutive patients, the most common ICU admission diagnosis was sepsis/septic shock, occurring in 54\%. At the time of RRT initiation, the median and interquartile range (IQR) serum creatinine level was 322 (221-432) $\mu \mathrm{mol} \cdot \mathrm{L}^{-1}$. The mean (SD) values for other parameters were as follows: Sequential Organ Failure Assessment (SOFA) score 13.4 (4.1), pH 7.25 (0.15), potassium 4.6 (1.0) $\mathrm{mmol} \cdot \mathrm{L}^{-1}$. Also, $64 \%$ fulfilled the serum creatinine-based criterion for Acute Kidney Injury Network (AKIN) stage 3. Severity of illness, measured using Acute Physiology and Chronic Health Evaluation (APACHE II) and SOFA scores, did not correlate with AKI severity as defined by the serum creatinine-based AKIN criteria. Median (IQR) time from hospital and ICU admission to the start of RRT was 2.0 (1.0-7.0) days and $1.0(0-2.0)$ day, respectively.

Conclusion Patients admitted to an ICU who were started on RRT generally had advanced AKI, high-grade illness severity, and multiorgan dysfunction. Also, they were started on RRT shortly after hospital presentation. We describe the current state of practice in Canada regarding the initiation of RRT for AKI in critically ill patients, which can inform the designs of future interventional trials.

M. T. James, MD - M. W. Walsh, MD

Foothills Medical Centre/Peter Lougheed Centre,

Calgary, AB, Canada

M. W. Walsh, MD

McMaster University, Hamilton, ON, Canada

A. A. House, MD - L. Moist, MD

University Hospital/Victoria Hospital, London Health Sciences

Centre, London, ON, Canada

D. E. Stollery, MD

Division of Critical Care Medicine, Grey Nuns Community

Hospital, Edmonton, AB, Canada

J. Barton, MD

St. Paul's Hospital, Saskatoon, SK, Canada

J.-P. Lafrance, MD

Hôpital Maisonneauve-Rosemont, Université de Montréal,

Montreal, QC, Canada

N. Pannu, MD

Division of Nephrology, University of Alberta,

Edmonton, AB, Canada

S. M. Bagshaw, MD ( $\square)$

Division of Critical Care Medicine, Faculty of Medicine and Dentistry, University of Alberta, 3C1.16 Walter C. Mackenzie Centre, 8440-122 Street, Edmonton, AB T6G 2B7, Canada e-mail: bagshaw@ualberta.ca

\section{Résumé}

Objectif Le moment optimal pour commencer le traitement de l'insuffisance rénale (TIR) en cas de lésion rénale aiguë (LRA) est inconnu. Définir les pratiques actuelles est nécessaire pour concevoir des études interventionnelles. Nous décrivons les pratiques canadiennes actuelles concernant la mise en route du TIR en cas de LRA.

Méthodes Une étude observationnelle de patients commençant un TIR pour LRA a été entreprise dans onze unités de soins intensifs (USI) à travers le Canada. Les auteurs ont collecté les données démographiques, les constatations cliniques et biologiques, les indications et le moment de début du TIR.

Résultats Parmi 119 patients consécutifs, le diagnostic le plus fréquent à l'admission en USI a été le sepsis/choc septique, chez $54 \%$ d'entre eux. Au moment du debut du

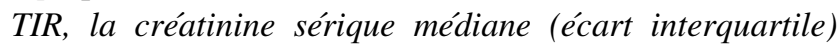
était 322 (221-432) $\mu \mathrm{mol} \cdot \mathrm{L}^{-1}$. Le score SOFA moyen (ET) était 13,4 (4,1), le pH était de 7,25 (0,15), la kaliémie était $4,6(1,0) \mathrm{mmol} \cdot \mathrm{L}^{-1}$ et $64 \%$ des patients répondaient à la définition de LRA de stade 3 du Acute Kidney Injury Network (AKIN), basée sur la créatinine sérique. La gravité de la maladie, mesurée à l'aide des scores APACHE II et SOFA, n'était pas corrélée à la gravité de la LRA définie selon les critères AKIN basés sur la créatinine sérique. Les délais médians (écarts interquartiles) écoulés entre l'hospitalisation ou l'admission dans l'USI et le début du TIR étaient, respectivement, de 2,0 (1,0 à 7,0) jours et $1,0(0$ à 2,0) jours.

Conclusion Les patients admis en USI chez qui un TIR était commencé avaient habituellement une LRA avancée, une maladie grave et une défaillance multi-organes; ils ont également reçu un TIR peu de temps après leur arrivée à l'hôpital. Nos constatations décrivent la situation actuelle des pratiques au Canada concernant le début du TIR pour des patients gravement atteints souffrant de LRA; elles pourront servir de base pour la conception d'études interventionnelles futures.

Severe acute kidney injury (AKI) is common in critical illness, occurring in 5-6\% of patients admitted to the intensive care unit (ICU). ${ }^{1}$ In addition to having an important impact on morbidity and health resource utilization, the mortality rate associated with severe AKI approaches $60 \% .^{1-7}$ Renal replacement therapy (RRT) is eventually used to treat most patients with severe AKI. ${ }^{1}$

Despite its widespread use, there are several controversies regarding the optimal delivery of RRT. Although recent large randomized controlled trials (RCTs) have better defined the appropriate dose of RRT for AKI, ${ }^{8,9}$ the 
optimal timing to initiate it remains uncertain despite many clinical studies. $^{10-25}$

Recent observational studies have suggested that earlier application of RRT may improve outcomes by mitigating end-organ damage due to the consequences of kidney failure, such as acidosis, azotemia, and fluid accumulation. $^{24,25}$ In the absence of data from suitably powered randomized trials, a recent systematic review comparing 'early' to 'late' initiation of RRT for AKI concluded that there was insufficient evidence to guide practice. ${ }^{26}$

Uncertainty about the optimal timing of RRT initiation for critically ill patients with AKI likely contributes to practice variation, which may affect patient outcomes. Accordingly, we conducted a multicentre prospective observational study to describe current practice patterns in Canada with respect to the timing of, and indications for, initiation of RRT in critically ill patients with AKI. We hypothesized that current practice may reflect the findings of recent observational studies that suggested a benefit of early RRT initiation. We also sought to describe current practice to inform the design of a prospective clinical trial to address the optimal timing of RRT initiation.

\section{Methods}

We report this study in accordance with the 'STrengthening the Reporting of OBservational studies in Epidemiology' (STROBE) statement. ${ }^{27}$

\section{Study design, setting, and population}

We conducted a multicentre observational study with prospective and retrospective data collection at nine academic and two community hospitals across Canada (refer to Table $\mathrm{S} 1$ in the supplementary material for details regarding study centres and enrolment). The Health Research Ethics Boards (HREBs) of all participating centres approved the study prior to commencement. As this study was strictly observational and did not influence the decision to start RRT or any other aspects of care, all HREBs waived the requirement for patient consent. Table S2, available only as electronic supplementary material, provides further details regarding HREB approval.

Planned enrolment at each centre was a convenience sample of ten consecutive, critically ill patients with AKI who were started on RRT. Enrolment occurred between August 2009 and June 2010, although not all centres recruited participants at the same time. All participants initiated on RRT for an AKI-related indication during their admission to ICU were included. Exclusion criteria were age less than $18 \mathrm{yr}$, RRT for a non-AKI indication (e.g., toxic ingestion), having undergone RRT prior to ICU admission, end-stage kidney disease undergoing chronic dialysis, and prior kidney transplantation.

Study definitions

Acute kidney injury was defined according to the Acute Kidney Injury Network (AKIN) classification, ${ }^{28}$ utilizing serum creatinine-based criteria only. The AKIN stage was determined using the most recent serum creatinine level during the six months that preceded hospital admission, when available, as baseline. ${ }^{29-31}$ Prehospitalization baseline serum creatinine values were unavailable for 45 patients $(38 \%)$. The baseline serum creatinine levels for these patients were assumed to be normal and estimated by back-calculation of values corresponding to an estimated glomerular filtration rate (eGFR) of $75 \mathrm{~mL} \cdot \mathrm{min}^{-1} / 1.73 \mathrm{~m}^{2}$ according to the abbreviated Modification of Diet in Renal Disease (MDRD) method, ${ }^{32}$ as suggested by the Acute Dialysis Quality Initiative (ADQI). ${ }^{33}$

Prehospitalization chronic kidney disease (CKD) was defined by an eGFR $<60 \mathrm{~mL} \cdot \mathrm{min}^{-1} / 1.73 \mathrm{~m}^{-2}$, calculated using the abbreviated MDRD equation, ${ }^{32}$ as recommended by the Kidney Disease Quality Initiative (K/DOQI) guidelines for CKD. ${ }^{34}$ The RRT included continuous or intermittent therapies_continuous renal replacement therapy (CRRT), intermittent hemodialysis (IHD), sustained low-efficiency dialysis (SLED)_but excluded acute peritoneal dialysis. Sepsis was defined according to consensus guidelines. ${ }^{35}$ Illness severity and organ failure were characterized by the Acute Physiology and Chronic Health Evaluation (APACHE) II score ${ }^{36}$ and the Sequential Organ Failure Assessment (SOFA) score. ${ }^{37,38}$ Based on a consensus statement by the AKIN, ${ }^{39}$ we defined several objectively measured 'traditional' indications for RRT initiation: serum urea $>35.7 \mathrm{mmol} \cdot \mathrm{L}^{-1}$; serum potassium $>6 \mathrm{mmol} \cdot \mathrm{L}^{-1}$; $\mathrm{pH}<7.15$.

\section{Study protocol}

Participants were identified prospectively by routine screening of all admissions to the participating ICUs. Eligible participants underwent a medical record review with documentation of baseline clinical, physiology, and laboratory data. Clinical data extracted included demographics (age, sex) and physiology and laboratory data at the time of initiation of RRT. We recorded details of premorbid and enrolment kidney function, diuretic and/or nephrotoxin exposure, use of mechanical ventilation, need for vasoactive drugs, illness severity (APACHE II), ${ }^{36}$ and organ failure (SOFA) $)^{37,38}$ scores. We recorded variables related to timing of RRT initiation (i.e., traditional indications) and 
clinical outcomes (i.e., length of stay in the ICU, ICU survival, and dialysis dependence at ICU discharge or death). Treating clinicians were also directly asked to indicate the indication(s) for RRT initiation from a list of choices: oliguria; diuretic-resistant oliguria; anuria; azotemia; uremic complications (e.g., encephalopathy); metabolic acidosis; metabolic alkalosis; hyperkalemia; other electrolyte disorder (with space provided to specify the exact disorder); pulmonary edema; extravascular volume overload. Clinicians were instructed to select as many indications as applicable. There was also an opportunity to specify 'other' indications that were not listed. All participant data were recorded on standardized forms.

Data analysis

Prior to analysis, data for each variable were qualitatively assessed for underlying distribution using box plots. Normally or near-normally distributed data for continuous variables were reported as means with standard deviations (SD). Nonnormally distributed data for continuous variables were reported as median values with interquartile ranges (IQRs). Categorical data were reported as proportions with frequencies. Missing data were censored from analyses; we report the number of subjects with available data for each variable.

We compared variables (e.g., serum potassium) between participants started on RRT for specific biochemical indications (e.g., hyperkalemia as defined by the treating clinician) to those of participants who were also started on RRT but not for that same indication using Student's $t$ tests. Significance testing was not adjusted for multiple testing. Two-sided $P$ values of $<0.05$ were considered statistically significant.

The one-way analysis of variance test was used to assess for differences in the mean APACHE II and SOFA scores amongst AKIN subgroups.

Statistical analysis was performed using SAS version 9.2 software (SAS Institute, Cary, NC, USA).

\section{Results}

\section{Baseline characteristics}

The study cohort consisted of 119 participants who started RRT while in the ICU. Baseline characteristics are detailed in Table 1 . The initial RRT modality used to treat participants was CRRT for 77\% (91/119), IHD for 17\% (20/119), and SLED for $7 \%(8 / 119)$.
Table 1 Baseline patients' characteristics $(n=119)$

\begin{tabular}{|c|c|}
\hline Age (yr) & $59(15)$ \\
\hline Female sex & $39(34)$ \\
\hline Body mass index $\left(\mathrm{kg} \cdot \mathrm{m}^{-2}\right)$ & $27(8.4)$ \\
\hline Baseline $\mathrm{eGFR}^{\dagger}\left(\mathrm{ml} / \mathrm{min} / 1.73 \mathrm{~m}^{2}\right)$ & $69(36)$ \\
\hline \multicolumn{2}{|l|}{ CKD Status* } \\
\hline Stage 3 or worse $\left(\mathrm{eGFR}<60 \mathrm{~mL} \cdot \mathrm{min}^{-1} / 1.73 \mathrm{~m}^{-2}\right)$ & $32(27)$ \\
\hline No baseline serum creatinine data available & 45 (38) \\
\hline \multicolumn{2}{|l|}{ Co-morbidities } \\
\hline Cardiovascular disease & $50(42)$ \\
\hline Hypertension & $65(55)$ \\
\hline Respiratory disease & $29(24)$ \\
\hline Liver disease & $18(15)$ \\
\hline Diabetes mellitus & $41(34)$ \\
\hline Malignancy & $16(13)$ \\
\hline Immunocompromised & $27(23)$ \\
\hline \multicolumn{2}{|l|}{ No. of co-morbidities } \\
\hline 0 & $12(10)$ \\
\hline 1 & 34 (29) \\
\hline 2 & $26(22)$ \\
\hline 3 & $32(27)$ \\
\hline$\geq 4$ & $15(13)$ \\
\hline \multicolumn{2}{|l|}{ Primary ICU admission diagnosis } \\
\hline Emergency surgery & 17 (14) \\
\hline \multicolumn{2}{|l|}{ Surgical } \\
\hline Any & $24(20)$ \\
\hline Cardiac & $7(6)$ \\
\hline Vascular & $6(5)$ \\
\hline Transplant & $6(5)$ \\
\hline General & $2(2)$ \\
\hline Other & $3(3)$ \\
\hline \multicolumn{2}{|l|}{ Medical } \\
\hline Any & $95(80)$ \\
\hline Sepsis/septic shock & $64(54)$ \\
\hline Cardiac & $7(6)$ \\
\hline Acute kidney injury & $6(5)$ \\
\hline Respiratory failure & $5(4)$ \\
\hline Liver failure & $3(3)$ \\
\hline Pancreatitis & $3(3)$ \\
\hline Other & $7(6)$ \\
\hline
\end{tabular}

ICU = intensive care unit; eGFR = estimated glomerular filtration rate; $\mathrm{CKD}=$ chronic kidney disease $; \mathrm{MDRD}=$ Modification of Diet in Renal Disease; K/DOQI = Kidney Disease Quality Initiative

Data are expressed as the mean (SD) for continuous variables or the number $(\%)$ for categorical variables

* Unless otherwise specified

${ }^{\dagger}$ Estimated glomerular filtration rate using four-variable MDRD method $^{31}$ with the serum creatinine value obtained within six months prior to admission $(n=74)$

* Chronic kidney disease classified according to K/DOQI guidelines. ${ }^{33}$ Patients with dialysis-requiring end-stage renal disease (stage 5 CKD) were excluded from this study 
Clinical and laboratory findings and ongoing treatment at RRT initiation

Table 2 summarizes selected clinical and laboratory findings and other treatments ongoing at the time of RRT initiation for AKI. The median (IQR) serum creatinine was $322(221-432) \mu \mathrm{mol} \cdot \mathrm{L}^{-1}$. Figure 1 shows a scatter plot of the values. The median increase in serum creatinine from

Table 2 Clinical and laboratory findings and ongoing treatments at the time of RRT initiation $(n=119) *$

\begin{tabular}{|c|c|}
\hline \multicolumn{2}{|l|}{ Clinical findings } \\
\hline APACHE II & $27(7)$ \\
\hline SOFA & $13.4(4.1)$ \\
\hline GCS & $7(3-11)$ \\
\hline Mean arterial pressure $(\mathrm{mmHg})$ & $75(13)$ \\
\hline Heart rate (beats $\cdot \min ^{-1}$ ) & $100(22)$ \\
\hline Respirator rate (breaths $\cdot \min ^{-1}$ ) & $22(6)$ \\
\hline $\mathrm{PaO}_{2}: \mathrm{FiO}_{2}$ ratio & $192(144-284)$ \\
\hline \multicolumn{2}{|l|}{ Cumulative urine output $(\mathrm{mL})$} \\
\hline Previous $24 \mathrm{hr}$ & $210(82-586)$ \\
\hline Previous $72 \mathrm{hr} * *$ & $1520(580-2932)$ \\
\hline \multicolumn{2}{|l|}{ Cumulative fluid balance (mL) } \\
\hline Previous $24 \mathrm{hr}^{\dagger \dagger}$ & $2578(1300-4565)$ \\
\hline Previous $72 \mathrm{hr}+$ & $5521(1749-8753)$ \\
\hline \multicolumn{2}{|l|}{ Laboratory findings } \\
\hline Serum creatinine, $\left(\mu \mathrm{mol} \cdot \mathrm{L}^{-1}\right)$ & $322(221-432)$ \\
\hline Serum urea $\left(\mathrm{mmol} \cdot \mathrm{L}^{-1}\right)$ & $20(13-27)$ \\
\hline Arterial $\mathrm{pH}$ & $7.25(0.15)$ \\
\hline Serum bicarbonate $\left(\mathrm{mmol} \cdot \mathrm{L}^{-1}\right)$ & $17(5)$ \\
\hline Serum potassium $\left(\mathrm{mmol} \cdot \mathrm{L}^{-1}\right)$ & $4.6(1.0)$ \\
\hline White blood cell count $\left(1000\right.$ cells $\left.\cdot \mathrm{mm}^{-3}\right)$ & $13.9(8.4-19.4)$ \\
\hline Hematocrit & $0.28(0.06)$ \\
\hline Platelets $\left(1000\right.$ cells $\left.\cdot \mathrm{mm}^{-3}\right)$ & $137(69-225)$ \\
\hline Lactate $\left(\mathrm{mmol} \cdot \mathrm{L}^{-1}\right)$ & $3.0(1.4-6.5)$ \\
\hline \multicolumn{2}{|l|}{ Treatments being received } \\
\hline Vasoactive medications & $90(76)$ \\
\hline Mechanical ventilation & $99(83)$ \\
\hline Diuretics within previous $24 \mathrm{hr}$ & $33(28)$ \\
\hline
\end{tabular}

APACHE II: Acute Physiology and Chronic Health Evaluation II; SOFA $=$ Sequential Organ Failure Assessment; GCS $=$ Glasgow Coma Scale; IQR = interquartile range

Data are expressed as the mean (SD) or the median (IQR) for continuous variables or the number (\%) for categorical variables

* Unless otherwise specified

- $n=104$ due to missing/unavailable data or due to initiation of renal replacement therapy (RRT) in less than $24 \mathrm{hr}$

** $n=46$ due to missing/unavailable data or due to initiation of RRT in $<72 \mathrm{hr}$

${ }^{\dagger} n=101$ due to missing/unavailable data or due to initiation of RRT in $<24 \mathrm{hr}$

林 $n=43$ due to missing/unavailable data or due to initiation of RRT in $<72 \mathrm{hr}$
Scatter Plot of Serum Creatinine Values at Time of RRT Initiation ( $n=119)$

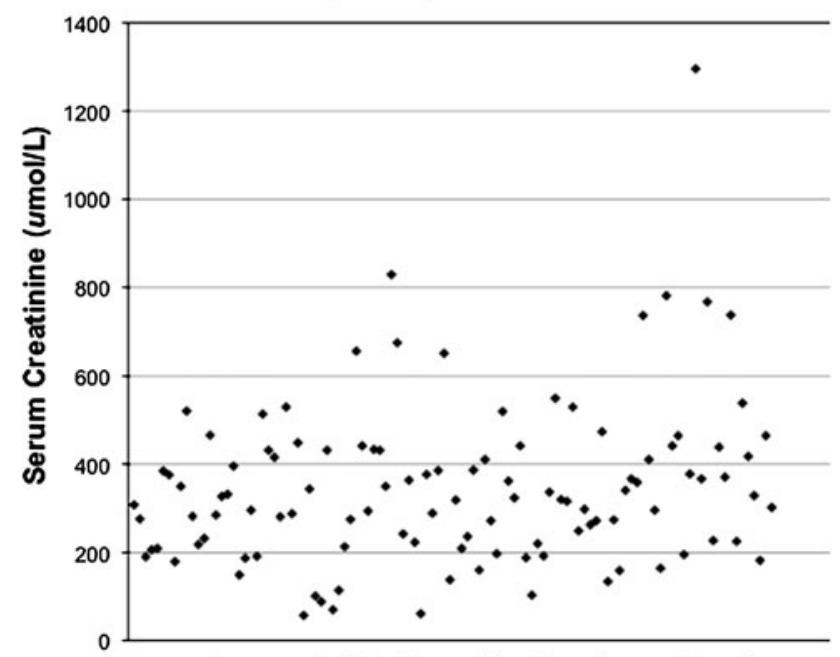

Sequential Patients (by Enrolment Date)

Fig. 1 Scatter plot of serum creatinine values at the time of renal replacement therapy (RRT) initiation $(n=119)$

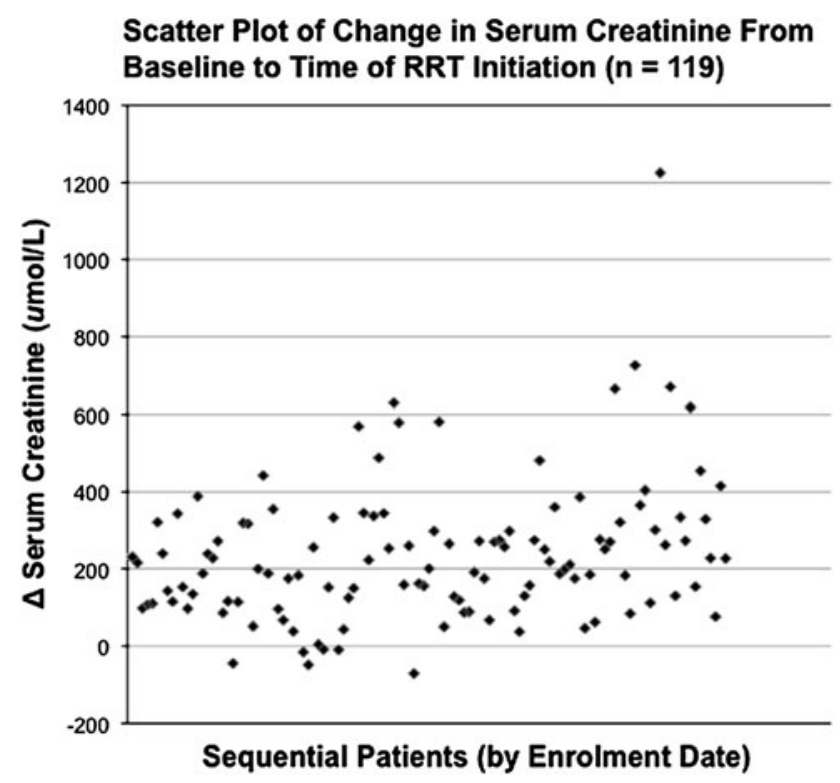

Fig. 2 Scatter plot of the change in serum creatinine levels from baseline to the time of renal replacement therapy (RRT) initiation $(n=119)$

baseline to that at RRT initiation was 237 (204-270) $\mu \mathrm{mol} \cdot \mathrm{L}^{-1}$. Figure 2 shows a scatter plot of the values.

Severity of AKI and severity of illness at hospital admission, ICU admission, and initiation of RRT

Table 3 summarizes the severity of AKI at hospital admission, ICU admission, and initiation of RRT. At the time of initiation, 5\% (6/119) did not fulfil the AKIN serum 
Table 3 Severity of AKI at time of hospital admission, ICU admission, and initiation of RRT according to median serum creatinine, median serum urea, and AKIN classification* $(n=119)$

\begin{tabular}{|c|c|c|c|}
\hline & \multicolumn{3}{|c|}{ Time of serum creatinine testing } \\
\hline & Hospital admission & ICU admission & Initiation of RRT \\
\hline Serum creatinine $\left(\mu \mathrm{mol} \cdot \mathrm{L}^{-1}\right)$, median $(\mathrm{IQR})$ & $173(97-344)$ & $236(138-354)$ & $322(221-432)$ \\
\hline Serum urea $\left(\mathrm{mmol} \cdot \mathrm{L}^{-1}\right)$, median $(\mathrm{IQR})$ & $13.4(17.4-21.8)$ & $14.7(8.0-23.0)$ & $20.4(12.8-27.3)$ \\
\hline \multicolumn{4}{|l|}{ AKIN stage, $n(\%)$} \\
\hline No. AKI & $43(36)$ & $25(21)$ & $6(5)$ \\
\hline 1 & $24(20)$ & $22(18)$ & $13(11)$ \\
\hline 2 & $13(11)$ & $22(18)$ & $24(20)$ \\
\hline 3 & $39(33)$ & $50(42)$ & 76 (64) \\
\hline
\end{tabular}

* To determine the AKIN classification, ${ }^{27}$ missing/unavailable baseline serum creatinine values for 45 patients were estimated according to Acute Dialysis Quality Initiative recommendations. ${ }^{32}$ Only serum creatinine-based criteria were used

$\mathrm{AKI}=$ acute kidney injury; $\mathrm{ICU}=$ intensive care unit; $\mathrm{RRT}=$ renal replacement therapy; AKIN = Acute Kidney Injury Network; $\mathrm{IQR}=$ interquartile range

creatinine criteria for AKI. Three of these patients would be classified as having AKIN-3 according to urine outputbased criteria. The remaining three had insufficient data $(n=2)$ or did not meet the urine output-based AKIN criteria $(n=1)$. The mean (SD) APACHE II scores at RRT initiation for those with no AKI, AKIN-1, AKIN-2, and AKIN-3 were 30.2 (4.2), 28.9 (6.3), 25.1 (6.4), and 27.6 (7.2), respectively. These scores did not differ among groups $(P=0.71)$. The mean $(\mathrm{SD})$ SOFA scores at the time of RRT initiation for those with no AKI, AKIN-1, AKIN-2, and AKIN-3 were 12.6 (4.1), 14.8 (3.0), 13.0 (4.7), and 13.5 (3.7), respectively. These scores also did not differ among groups $(P=0.98)$.

Time to initiation of RRT following hospital and ICU admissions

Fig. 3 illustrates the median times to initiation of RRT after hospital admission, and Figure 4 illustrates the median times to initiation of RRT after ICU admission. For the six patients who did not meet serum creatinine-based AKIN criteria for AKI at RRT initiation, the median (IQR) time from ICU admission to the start of RRT was 0.5 days (0-4.0 days).

Indications for initiation of RRT

The median (IQR) number of indications for RRT initiation was 2 (2-3) per patient; $20 \%$ had one indication, $30 \%$ had two indications, $31 \%$ had three indications, and $18 \%$ had four or more indications. Table 4 summarizes clinicianreported indications for initiation of RRT and the median values of variables related to those indications. With the exception of 'peripheral edema,' for all clinician-reported indications for RRT initiation, the mean of the relevant variable (e.g., serum potassium level for the indication of
Median Time From Hospital Admission to Start of RRT According to AKIN Classification

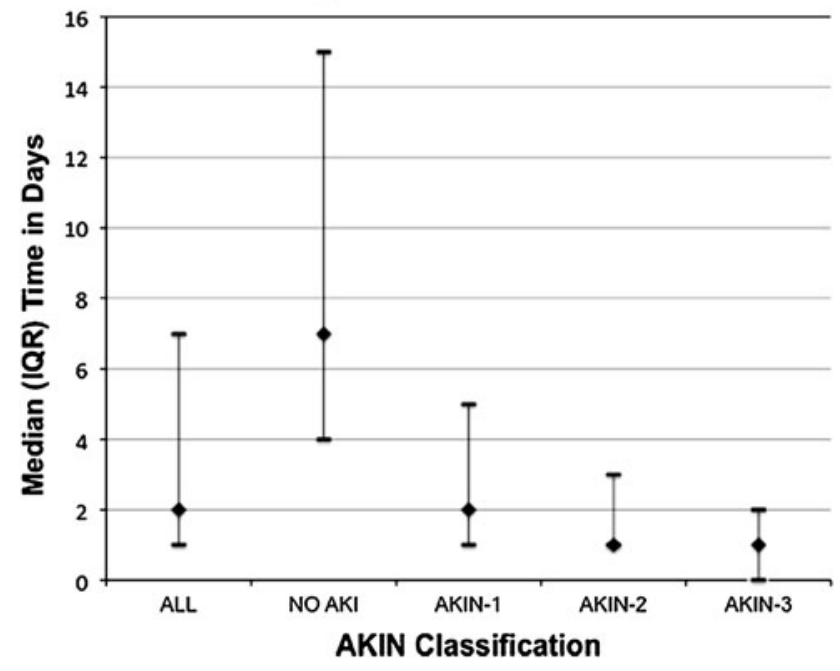

Fig. 3 Median time from hospital admission to the start of renal replacement therapy (RRT) according to the Acute Kidney Injury Network (AKIN) classification

hyperkalemia) was significantly different for patients with a particular indication than for those without that indication.

Table 5 summarizes the frequency with which patients started RRT for AKI according to several 'traditional' indications (as discussed in the Methods section). It also demonstrates the frequency with which clinicians reported that a related indication for initiation was present at the same time as a traditional indication (e.g., a clinicianreported indication of metabolic acidosis when the traditional indication of $\mathrm{pH}<7.15$ was present).

The traditional indications of serum potassium $>$ $6 \mathrm{mmol} \cdot \mathrm{L}^{-1}, \mathrm{pH}<7.15$, and serum urea $>35.7 \mathrm{mmol} \cdot \mathrm{L}^{-1}$ 


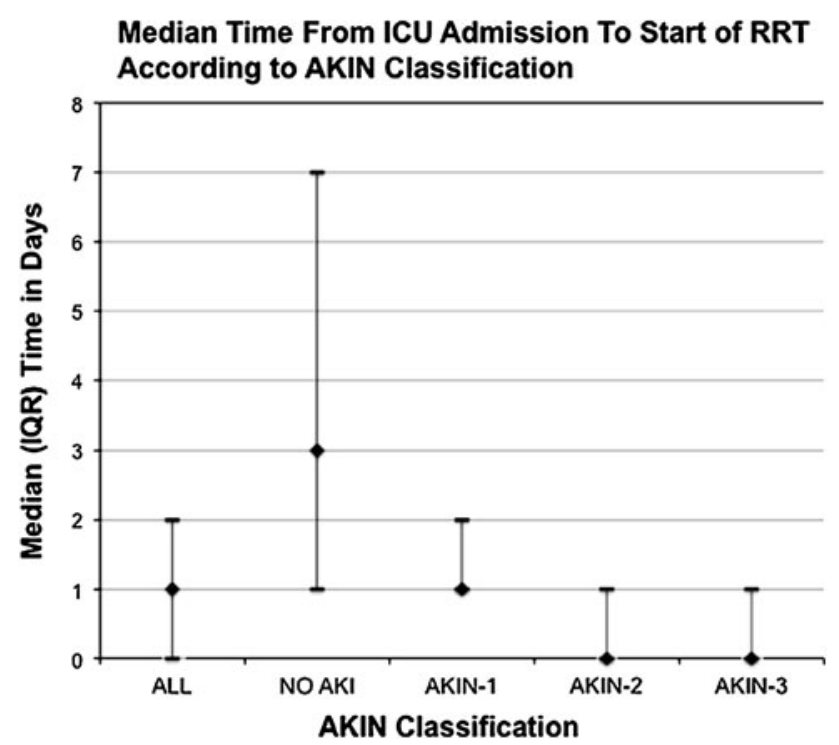

Fig. 4 Median time from intensive care unit (ICU) admission to the start of renal replacement therapy (RRT) according to the Acute Kidney Injury Network (AKIN) classification

were infrequently observed at the time of RRT initiation. The most frequently observed traditional indication was $\mathrm{pH}<7.15$, which was present in $24(20 \%)$ of 119 patients.

\section{Outcomes}

Death occurred in the ICU for $42 \%$ of patients (50/119). Altogether, 34\% (40/119) had their RRT stopped in the ICU because of renal recovery.

\section{Discussion}

We found that critically ill patients started on RRT generally had advanced AKI, high illness severity, and multiorgan dysfunction. They were started on RRT early after hospitalization and ICU admission. Only a small number of patients were started on RRT for a traditional indication; and the serum creatinine level at RRT initiation varied greatly. Our findings suggest that serum creatinine may be relatively unimportant in clinicians' decisions about when to initiate RRT. Thus, trials of RRT timing should consider clinicians' operational definitions of common indications for RRT initiation. For example, the mean potassium level of patients started on RRT for a clinician-reported indication of hyperkalemia was $5.9 \mathrm{mmol} \cdot \mathrm{L}^{-1}$. Thus, clinicians would be unlikely to accept potassium $>5.9 \mathrm{mmol} \cdot \mathrm{L}^{-1}$ as an inclusion criterion for an RCT of 'early' $v s$ 'standard-of-care' RRT initiation.

Table 4 Clinician-reported indications for initiation of RRT and the mean value of relevant variables for patients with and without those indications $(n=119)$

\begin{tabular}{lllllc}
\hline $\begin{array}{l}\text { Clinician-reported } \\
\text { indication for initiation } \\
\text { of RRT }\end{array}$ & No. (\%) & Relevant variable & $\begin{array}{l}\text { Mean value for } \\
\text { patients with the } \\
\text { indication }\end{array}$ & $\begin{array}{l}\text { Mean value for } \\
\text { patients without } \\
\text { the indication }\end{array}$ & $\begin{array}{l}\text { Difference in means } \\
(95 \% \text { CI) }\end{array}$ \\
\hline Oligoanuria & $86(72)$ & Urine output prev. $24 \mathrm{hr}(\mathrm{mL})$ & 380 & 934 & $-554^{*}(-189$ to -919$)$ \\
Metabolic acidosis & $57(48)$ & Arterial pH & 7.16 & 7.33 & $-0.17 *(-0.13$ to -0.22$)$ \\
Uremia/azotemia & $40(34)$ & Serum urea $\left(\mathrm{mmol} \cdot \mathrm{L}^{-1}\right)$ & 27.5 & 19.9 & $7.5 *(2.8$ to 12.2$)$ \\
Pulmonary edema & $34(29)$ & $\mathrm{PaO}_{2} / \mathrm{F}_{\mathrm{I}} \mathrm{O}_{2}$ ratio & 191 & 234 & $-43 *(-2$ to -90$)$ \\
Peripheral edema & $35(29)$ & Fluid balance prev. $24 \mathrm{hr}(\mathrm{mL})$ & 4154 & 3295 & $859(-1140$ to 2085$)$ \\
Hyperkalemia & $26(22)$ & Serum potassium $(\mathrm{mmol} / \mathrm{L})$ & 5.9 & 4.2 & $1.7 *(1.4$ to 2.0$)$ \\
\hline
\end{tabular}

$\mathrm{RRT}=$ renal replacement therapy; $\mathrm{CI}=$ confidence interval

* $P<0.05$ using two-tailed Student's $t$ test

Table 5 Frequency of initiation of RRT according to 'traditional' indications and agreement of clinician-reported indications for initiation of RRT for patients with 'traditional' indications present at the time of initiation $(n=119)$

\begin{tabular}{lllr}
\hline $\begin{array}{l}\text { 'Traditional' indication* } \\
\text { for initiation of RRT }\end{array}$ & $\begin{array}{l}\text { 'Traditional' indication } \\
\text { present at time of initiation } \\
\text { of RRT } \\
\text { No. }(\%)\end{array}$ & $\begin{array}{l}\text { Clinician-reported indications for initiation of RRT for } \\
\text { patients with 'traditional' indications present }\end{array}$ & No. (\%) \\
\hline Serum potassium $>6.0 \mathrm{mmol} \cdot \mathrm{L}^{-1 \dagger}$ & $11(9)$ & Hyperkalemia & $10(91)$ \\
$\mathrm{pH}<7.15$ & $24(20)$ & Metabolic acidosis & $23(96)$ \\
Serum urea $>35.7 \mathrm{mmol} \cdot \mathrm{L}^{-1}$ & $12(10)$ & Uremia/azotemia & $6(50)$
\end{tabular}

* As suggested in a consensus statement by the Acute Kidney Injury Network ${ }^{8}$

$\dagger$ With or without electrocardiography changes of hyperkalemia 
We also found significant variation in practice regarding the severity of AKI defined by serum creatinine levels (Fig. 1), changes in serum creatinine levels from baseline (Fig. 2), or the serum creatinine-based AKIN criteria (Table 3 ) at the time of RRT initiation. In all, $64 \%$ of patients had severe AKI (AKIN-3), whereas $16 \%$ had only mild AKI (AKIN-1) or did not meet the AKIN criteria for AKI. Although not statistically significant, patients with less-severe AKI according to AKIN stage generally had lower serum $\mathrm{pH}$ and higher APACHE II and SOFA scores. The insensitivity of creatinine-based methods to diagnose and classify AKI in the context of critical illness has been shown. ${ }^{40}$ The wide variability in serum creatinine values at the time of RRT initiation is consistent with the results of a recent survey of RRT initiation practices in Canada, in which $43 \%$ of clinicians indicated that they do not consider the serum creatinine level when determining whether to start RRT for AKI. ${ }^{41}$ Thus, an absolute serum creatinine threshold is unlikely to be useful as an RRT initiation trigger in research protocols.

\section{Comparison with previous studies}

The largest study that describes the timing of initiation of RRT for AKI was the Beginning and Ending Supportive Therapy for the Kidney (BEST Kidney) study. ${ }^{1,10}$ It was an international, multicentre, prospective observational study of critically ill patients with AKI who were in the ICU. ${ }^{1}$ The BEST Kidney study enrolled 1,238 patients (including 93 from two centres in Canada) and provided important data regarding clinical and laboratory findings at the time RRT was started for AKI. ${ }^{1,10}$

Compared to the BEST Kidney study, in which the median (IQR) time from hospital admission to the start of RRT was five days, the median time in our study was only two days. The interval from ICU admission to the start of RRT was also shorter. ${ }^{10}$ These findings may be partially explained by the relatively high illness severity observed for the patients in our study compared with those enrolled in the BEST Kidney study. Another factor is that nine of the 11 hospitals included in our study are tertiary hospitals, and some patients may have been transferred from peripheral hospitals specifically for RRT.

Despite patients undergoing RRT more quickly, as indicated above, the severity of their illness was worse than what was reported by the BEST Kidney study, whose patients had a mean SOFA score of 10.9 vs 13.4 in our study. ${ }^{10}$ Even with the higher burden of organ dysfunction, the observed mortality was markedly lower in our study than that in the BEST Kidney study (42\% vs 52\%). This likely related to differences in the case mix between the studies, although it leads to speculation that the observed difference may be due to differences in the rapidity of RRT initiation.
Study limitations and strengths

A key strength of our study is the prospective recording of both clinical/laboratory data (correlated with 'traditional' indications for RRT) coupled with clinician-reported triggers for initiation of RRT. These linked data may help refine the eligibility criteria for randomized trials to determine the timing of RRT initiation. We also believe that our multicentre data collection is likely to be generalizable to Canadian practice.

There are also limitations to our study. First, we did not capture data for all of the patients admitted to the ICU with AKI or who developed AKI while in the ICU yet did not undergo RRT. Therefore, we cannot compare clinical and biochemical features over time that distinguish patients with AKI who start RRT compared to those who do not ${ }^{42}$; nor can we comment on outcomes of patients with severe AKI who did not undergo RRT. ${ }^{43}$ Second, we did not determine whether patients were transferred from regional hospitals specifically for RRT; thus, we may have misclassified the starting time for these patients and decreased the measured time from hospital and ICU admission to RRT. However, a prior study of clinical factors at the time of RRT initiation found that $29.9 \%$ of patients were transferred from a regional hospital for RRT, and there was no significant difference in time to RRT initiation according to transfer status. ${ }^{44}$ Therefore, it is less likely that the subgroup of 'transferred in' patients significantly biased our findings with respect to time to start of RRT. Third, we did not capture the exact time (only the date) of hospital and ICU admissions and RRT initiation. Accordingly, our estimates of the start time of RRT after admission may be imprecise. Fourth, our study utilized a convenience sample of approximately ten consecutive patients at each site. This limited the ability to perform multilevel models to determine the relative importance of hospital vs patient level factors in practice variability; nonetheless, our data suggest a wide variation in what constitutes a trigger for RRT initiation in the ICU. Finally, specific patient subgroups (e.g., cardiac surgery patients) may have been underrepresented in our study compared to those in all Canadian ICU beds. Although significant differences were not observed for patients with medical versus surgical ICU admission diagnoses in terms of severity of illness scores and serum creatinine and urea levels at the time of RRT initiation or time to initiation of RRT from hospital and ICU admissions (data not shown), the relatively small number of surgical admissions overall ( $n=24)$ limited our ability to conduct meaningful subgroup analysis across that variable.

In conclusion, this study provides detailed information regarding the current state of practice with respect to the timing of initiation of RRT for AKI in critically ill patients 
in Canada. These data show that patients undergoing RRT for AKI generally have advanced AKI, high degree of illness severity, and multiorgan dysfunction; they also start RRT early after hospital presentation and ICU admission. The severity of AKI, as determined based on the serum creatinine level at the time of RRT initiation, was highly variable, implying that using the serum creatinine level as a trigger for RRT may be a flawed policy. These data are important to best inform the design of interventional studies of the optimal timing for RRT initiation in critically ill patients with AKI.

Acknowledgements The authors acknowledge the contribution of Ms. Ayodele Odutayo who assisted with data collection at Sunnybrook Health Sciences Centre. Dr. Clark is supported by a Clinical Fellowship Award from the Kidney Research Centre, Ottawa Hospital Research Institute. Dr. Wald is supported by a Randomized Controlled Trial Mentoring Award from the Canadian Institutes of Health Research. Dr. Bagshaw is supported by a Canada Research Chair in Critical Care Nephrology and a Clinical Investigator Award from Alberta Innovates - Health Solutions.

\section{References}

1. Uchino S, Kellum JA, Bellomo R, et al. Acute renal failure in critically ill patients: a multinational, multicenter study. JAMA 2005; 294: 813-8.

2. Hoste EA, Clermont $G$, Kersten A, et al. RIFLE criteria for acute kidney injury are associated with hospital mortality in critically ill patients: a cohort analysis. Crit Care 2006; 10: R73.

3. Ahlstrom A, Tallgren M, Peltonen $S$, Rasanen P, Pettila $V$. Survival and quality of life of patients requiring acute renal replacement therapy. Intensive Care Med 2005; 31: 1222-8.

4. Bagshaw SM, Laupland KB, Doig CJ, et al. Prognosis for longterm survival and renal recovery in critically ill patients with severe acute renal failure: a population-based study. Crit Care 2005; 9: R700-9.

5. Korkeila M, Ruokonen E, Takala J. Costs of care, long-term prognosis and quality of life in patients requiring renal replacement therapy during intensive care. Intensive Care Med 2000; 26 : 1824-31.

6. Manns B, Doig CJ, Lee H, et al. Cost of acute renal failure requiring dialysis in the intensive care unit: clinical and resource implications of renal recovery. Crit Care Med 2003; 31: 449-55.

7. Morgera S, Kraft AK, Siebert G, Luft FC, Neumayer HH. Longterm outcomes in acute renal failure patients treated with continuous renal replacement therapies. Am J Kidney Dis 2002; 40: 275-9.

8. VA/NIH Acute Renal Failure Trial Network; Palevsky PM, Zhang $J H, O$ 'Connor $T Z$, et al. Intensity of renal support in critically ill patients with acute kidney injury. N Engl J Med 2008; 359: 7-20.

9. RENAL Replacement Therapy Study Investigators, Bellomo $R$, Cass A, Cole L, et al. Intensity of continuous renal-replacement therapy in critically ill patients. N Engl J Med 2009; 361: 1627-38.

10. Bagshaw SM, Uchino S, Bellomo $R$, for the Beginning and Ending Supportive Therapy for the Kidney (BEST Kidney) Investigators, et al. Timing of renal replacement therapy and clinical outcomes in critically ill patients with severe acute kidney injury. J Crit Care 2009; 24: 129-40.
11. Kornhall $S$. Acute renal failure in surgical disease with special regard to neglected complications. A retrospective study of 298 cases treated during the period 1960-1968. Acta Chir Scand Suppl 1971; 419: 3-64.

12. Kleinknecht D, Jungers $P$, Chanard J, Barbanel C, Ganeval D, Rondon-Nucete $M$. Factors influencing immediate prognosis in acute renal failure, with special reference to prophylactic hemodialysis. Adv Nephrol Necker Hosp 1971; 1: 207-30.

13. Kleinknecht D, Jungers $P$, Chanard J, Barbanel C, Ganeval D. Uremic and non-uremic complications in acute renal failure: evaluation of early and frequent dialysis on prognosis. Kidney Int 1972; 1: 190-6.

14. Conger JD. A controlled evaluation of prophylactic dialysis in post-traumatic acute renal failure. J Trauma 1975; 15: 1056-63.

15. Lange HW, Aeppli DM, Brown DC. Survival of patients with acute renal failure requiring dialysis after open heart surgery: early prognostic indicators. Am Heart J 1987; 113: 1138-43.

16. Cosentino $F$, Chaff C, Piedmonte $M$. Risk factors influencing survival in ICU acute renal failure. Nephrol Dial Transplant 1994; 9(Suppl 4): 179-82.

17. Gettings $L G$, Reynolds $H N$, Scalea $T$. Outcome in post-traumatic acute renal failure when continuous renal replacement therapy is applied early vs. late. Intensive Care Med 1999; 25: 805-13.

18. Kresse S, Schlee H, Deuber HJ, Koall W, Osten B. Influence of renal replacement therapy on outcome of patients with acute renal failure. Kidney Int 1999; 56: S75-8.

19. Splendiani G, Mazzarella V, Cipriani S, Zazzaro D, Casciani CU. Continuous renal replacement therapy: our experience in intensive care unit. Ren Fail 2001; 23: 259-64.

20. Bouman CS, Oudemans-Van Straaten HM, Tijssen JG, Zandstra $D F$, Kesecioglu J. Effects of early high-volume continuous venovenous hemofiltration on survival and recovery of renal function in intensive care patients with acute renal failure: a prospective, randomized trial. Crit Care Med 2002; 30: 2205-11.

21. Elahi MM, Lim MY, Joseph RN, Dhannapuneni RR, Spyt TJ. Early hemofiltration improves survival in post-cardiotomy patients with acute renal failure. Eur J Cardiothorac Surg 2004; 26: 1027-31.

22. Demirkilic U, Kuralay E, Yenicesu M, et al. Timing of replacement therapy for acute renal failure after cardiac surgery. J Card Surg 2004; 19: 17-20.

23. Liu KD, Himmelfarb J, Paganini EP, et al. Timing of initiation of dialysis in critically ill patients with acute kidney injury. Clin J Am Soc Nephrol 2006; 1: 915-9.

24. Matson J, Zydney A, Honore PM. Blood filtration: new opportunities and the implications of systems biology. Crit Care Resusc 2004; 6: 209-17.

25. Ricci Z, Ronco $C$, D'Amico $G$, et al. Practice patterns in the management of acute renal failure in the critically ill patient: an international survey. Nephrol Dial Transplant 2006; 21: 690-6.

26. Karvellas $C$, Farhat M, Sajjad I, et al. A comparison of early versus late initiation of renal replacement therapy in critically ill patients with acute kidney injury: a systematic review and metaanalysis. Crit Care 2011; 15: R72.

27. von Elm E, Altman DG, Egger M, STROBE Initiative, et al. The Strengthening the Reporting of Observational Studies in Epidemiology (STROBE) statement: guidelines for reporting observational studies. J Clin Epidemiol 2008; 61: 344-9.

28. Mehta RL, Kellum JA, Shah SV, Acute Kidney Injury Network, et al. Report of an initiative to improve outcomes in acute kidney injury. Crit Care 2007; 11: R31.

29. Hsu CY, Ordonez JD, Chertow GM, Fan D, McCulloch CE, Go $A S$. The risk of acute renal failure in patients with chronic kidney disease. Kidney Int 2008; 74: 101-7.

30. Lui KD, Lo L, Hsu CY. Some methodological issues in studying the long-term renal sequelae of acute kidney injury. Curr Opin Nephrol Hypertens 2009; 18: 241-5. 
31. Murray PT, Liu KD. Acute kidney injury and critical care nephrology: definition of acute kidney injury. NephSAP 2011; 10: 201-7.

32. Levey AS, Bosch JP, Lewis JB, Greene T, Rogers N, Roth D. A more accurate method to estimate glomerular filtration rate from serum creatinine: a new prediction equation. Modification of Diet in Renal Disease Study Group. Ann Intern Med 1999; 130: 461-70.

33. Bellomo R, Ronco C, Kellum J, et al. Acute renal failure - definition, outcome measures, animal models, fluid therapy and information technology needs: the Second International Consensus Conference of the Acute Dialysis Quality Initiative (ADQI) Group. Crit Care 2004; 8: R204-12.

34. National Kidney Foundation. K/DOQI clinical practice guidelines for chronic kidney disease: evaluation, classification, and stratification. Am J Kidney Dis 2002; 39(2 Suppl 1): S1-266.

35. Levy MM, Fink MP, Marshall JC, et al. 2001 SCCM/ESICM/ ACCP/ATS/SIS international sepsis definitions conference. Intensive Care Med 2003; 29: 530-8.

36. Knaus WA, Draper EA, Wagner DP, Zimmerman JE. APACHE II: a severity of disease classification system. Crit Care Med 1985; 13: 818-29.

37. Vincent JL, Moreno R, Takala J, et al. The SOFA (Sepsis-related Organ Failure Assessment) score to describe organ dysfunction/ failure. On behalf of the Working Group on Sepsis-Related
Problems of the European Society of Intensive Care Medicine. Intensive Care Med 1996; 22: 707-10.

38. Vincent JL, Ferreira F, Moreno R. Scoring systems for assessing organ dysfunction and survival. Crit Care Clin 2000; 16: 353-66.

39. Gibney N, Hoste E, Burdmann EA, et al. Timing of initiation and discontinuation of renal replacement therapy in AKI: unanswered key questions. Clin J Am Soc Nephrol 2008; 3: 876-80.

40. Waikar SS, Betensky RA, Bonventre JV. Creatinine as the gold standard for kidney injury biomarker studies? Nephrol Dial Transplant 2009; 24: 3263-5.

41. Clark E, Wald R, Walsh M, Bagshaw SM; for the Canadian Acute Kidney Injury (CANAKI) Investigators. Timing of initiation of renal replacement therapy for acute kidney injury: a survey of nephrologists and intensivists in Canada. Nephrol Dial Transplant 2011; doi: 10.1093/ndt/gfr740.

42. Palevsky $P M$. Indications and timing of renal replacement therapy in acute kidney injury. Crit Care Med 2008; 36(4 Suppl): S224-8.

43. Schneider AG, Uchino $S$, Bellomo $R$. Severe acute kidney injury not treated with renal replacement therapy: characteristics and outcomes. Nephrol Dial Transplant 2012; 27: 947-52.

44. Bagshaw SM, Wald R, Barton J, et al. Clinical factors associated with initiation of renal replacement therapy in critically ill patients with acute kidney injury - a prospective multicenter observational study. J Crit Care 2012; 27: 268-75. 